http://dx.doi.org/10.35381/r.k.v4i1.459

\title{
Plan de expansión empresarial para la Empresa Transnexos del Grupo Industrial Graiman
}

\section{Business expansion plan for the Transnexos Company of the Graiman Industrial Group}

\author{
Jhoana Alexandra Picón Vizhñay \\ jpiconv@psg.ucacue.edu.ec \\ Universidad Católica de Cuenca \\ Ecuador \\ https://orcid.org/0000-0001-9553-5937 \\ Juan Carlos Erazo Álvarez \\ jcerazo@ucacue.edu.ec \\ Universidad Católica de Cuenca \\ Ecuador \\ https://orcid.org/0000-0001-6480-2270 \\ Cecilia Ivonne Narváez Zurita \\ inarvaez@ucacue.edu.ec \\ Universidad Católica de Cuenca \\ Ecuador \\ https://orcid.org/0000-0002-7437-9880
}

Recibido: 10 de agosto de 2019

Aprobado: 30 de agosto de 2019

\begin{abstract}
RESUMEN
Se considera al plan de negocios de expansión una herramienta en donde se involucren diferentes análisis de los procesos necesarios para llevarse a cabo en un período dado de tiempo y permita el cumplimiento de los objetivos planteados. El presente trabajo de investigación realizada en la unidad de análisis la empresa Transnexos, la misma tiene una baja rentabilidad debido a la limitación de sus clientes siendo el 99\% las empresas del Grupo Industrial Graiman (GIG). Se orientó a realizar un plan de negocios de expansión en la que se aplicó la investigación cuantitativa con un alcance descriptivo. Se realizó un estudio de mercado en el que se aplicó una encuesta para determinar la viabilidad de brindar el servicio de transporte a clientes potenciales, el estudio financiero estableció que se requiere una inversión de 1.273 .000 mil dólares para adquisición de
\end{abstract}


vehículos que cubran las rutas de los clientes potenciales. Se identificó la evaluación del VAN positivo de 26.114 dólares y una TIR de $9.07 \%$ mostrando la factibilidad del proyecto.

Descriptores: Expansión; Plan; Empresa; Herramienta; Transporte.

\begin{abstract}
The expansion business plan is considered a tool in which different analyzes of the processes necessary to be carried out in a given period of time and allow the fulfillment of the stated objectives are involved. The present research work carried out in the analysis unit of the company Transnexos, has a low profitability due to the limitation of its clients, $99 \%$ being the companies of the Graiman Industrial Group (GIG). It was oriented to carry out an expansion business plan in which quantitative research was applied with a descriptive scope. A market study was conducted in which a survey was applied to determine the feasibility of providing the transportation service to potential customers, the financial study established that an investment of 1,273,000 thousand dollars is required to acquire vehicles that cover the routes of potential customers. The evaluation of the positive NPV of $\$ 26,114$ and an IRR of $9.07 \%$ were identified showing the feasibility of the Project.
\end{abstract}

Descriptors: Expansion; Plan; Company; Tool; Transportation.

\title{
INTRODUCCIÓN
}

El transporte es un factor muy importante que mueve al sector económico, para brindar este servicio existen gremios asociados que regulan precios de acuerdo con el volumen de ventas que pueden incrementar o disminuir.

El mercado nacional cuenta con una amplia gama de camiones de carga, con tecnología de punta satisfaciendo las necesidades del sector tanto por capacidad como en seguridad. Según, La Corporación Financiera Nacional (CFN), en 2016 Ecuador contó con 4.703 empresas de transporte de este tipo, como se puede apreciar en la tabla 1, las mismas que emplearon a 26.505 personas (CFN, 2017). 


\section{Tabla 1}

Transporte de carga por carretera

\begin{tabular}{|c|c|c|}
\hline $\begin{array}{l}\text { Transporte de carga } \\
\text { por } \quad \text { carretera } \\
(\mathbf{H} 4923)\end{array}$ & \# Empresas 2016 & $\begin{array}{l}\# \quad \text { Empleados } \\
2016\end{array}$ \\
\hline Grande & 66 & 4,991 \\
\hline Mediana & 311 & 4,957 \\
\hline Micro & 2,923 & 8,580 \\
\hline Pequeña & 1,403 & 7,977 \\
\hline Total general & 4,703 & 26,505 \\
\hline
\end{tabular}

Fuente: CFN, 2017.

Total general

El sector de transporte y almacenamiento, en el año 2016 suma $\$ 4,713$ millones, con una participación en el total del PIB de 6.8\%, como se puede valorar en la tabla 2 , se evidencia un crecimiento del $0.12 \%$ respecto al año 2015 (CFN, 2017).

\section{Tabla 2}

PIB del Sector del Transporte

Año Transporte Almacenamiento (Millones USD 2007)

2013

2014

2015

2016 y PIB Total (Millones USD Participación

de de 2007)

\begin{tabular}{lll}
4,577 & 67,546 & $6.78 \%$ \\
4,807 & 70,243 & $6.84 \%$ \\
4,707 & 70,354 & $6.69 \%$ \\
4,713 & 69,321 & $6.80 \%$ \\
\hline
\end{tabular}

Fuente: CFN, 2017.

Al momento existen 751 unidades operando legalmente en el área rural, esta modalidad según la ley es interprovincial es decir podrá realizar viajes desde y hacia los cantones. Debido a que brinda servicio a las áreas rurales del cantón Cuenca, no se conceden paradas para compañía alguna en el área urbana (GAD, 2015).

La unidad de análisis de esta investigación es la empresa Transnexos, es una prestadora de servicios de transporte de carga pesada que tiene como propósito atender las necesidades de movilidad de este tipo en toda la cadena de valor de la industria 
manufacturera y comercial del Grupo Industrial Graiman (GIG), de forma eficiente, garantizando las operaciones de sus clientes. La empresa nace el 26 de Julio del año 2011 , en respuesta a la necesidad de contar con una empresa de transporte que pueda brindar un servicio que cumpla con todos los parámetros establecidos por las diferentes entidades de control del Estado. Para operar su flota Transnexos cuenta con transportistas debidamente calificados y certificados.

En la actualidad la empresa brinda el servicio de transporte a nivel nacional, siendo el 99\% de los clientes las empresas del GIG. El porcentaje de clientes es muy restringido para la empresa y no permite tener un crecimiento en los resultados financieros, por lo que surge la necesidad de diseñar un plan de negocios de expansión en donde se incorpore una nueva línea de ingresos para incrementar los clientes potenciales (externos GIG), empleando técnicas administrativas de modo que permitan optimizar las operaciones que se deriva en los siguientes puntos de mejora: estructura de costos de transporte relacionados a plan de ruta adecuada, análisis y estrategias de procesos, tecnología, personas, costo-beneficio de administración de flota, con el objetivo de incrementar su rentabilidad.

\section{La expansión de los negocios, mediante la utilización de un plan innovador}

Al hablar de innovación se puede definir "como la aplicación o utilización de nuevas ideas, productos o servicios" (Maqueda, 2010, p.20). No sería valido si solo se introduce al mercado el producto o servicio, la estrategía estaría en saberlo como introducirlo y sea aceptado. Todo modelo para las empresas modernas deben considerar el proceso innovador, el mismo debe abarcar desde la concepción de la idea, pasar las pruebas de viabilidad técnica y ecónomica, terminando con la comercialización del nuevo producto o servicio (Maqueda, 2010).

Al buscar innovar un negocio, se debe analizar sobre estrategías para expandir o incrementar nuevas áreas del negocio de manera que se puedan crear oportunidades para alcanzar el crecimiento del mismo. Es necesario desarrollar de un plan de negocios 
innovador que sirva como guía, de manera que se puedan aclarar y considerar todos los procesos requeridos para el cumplimiento de los objetivos.

Un plan de negocios innovador también puede verse como el documento en el que se identifican claramente los objetivos de la empresa, las rutas a seguir para alcanzar los objetivos, los obstáculos que se enfrentarán en el camino, la herramienta que utilizará el empresario para superar los obstáculos y los mecanismos para medir el avance del proceso. De tal manera que un plan de negocios innovador es un instrumento que nos permite llevar a cabo o capitalizar la idea del proyecto. (Castelán y Oros, 2011, p.2). Con el desarrollo del plan de negocios innovador se evalúa la posibilidad de crear una nueva empresa, empezando con la formulación de una idea de negocio a partir del análisis del entorno. En la figura 1 se detalla el proceso.

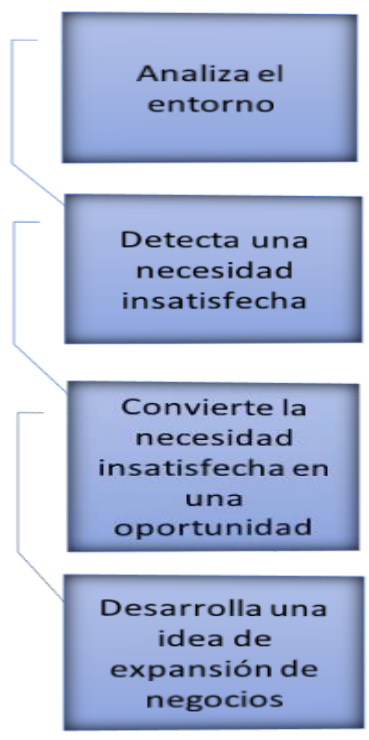

Figura 1. Proceso de expansión de negocio

Fuente: (Weinberger, 2009).

El plan de negocios innovador radica en que es una herramienta que permite a la gerencia, la adecuada gestión de las operaciones en un periodo dado de tiempo para el cumplimiento de los objetivos, una empresa sin un plan sería como un vehículo sin 
dirección (Puente y Carrasco, 2017). Por ello, al plan de negocios innovador se lo ve como una guía a seguir por el empresario o usuario final recolectando las necesidades, estrategias y metas a alcanzar. El plan de negocios innovador ayuda a estructurar la forma de cómo deben operar las distintas áreas de la empresa, de manera que se puedan alcanzar los objetivos sea sinérgica y eficientemente (Viniegra, 2007). Así mismo, Blanco Bello, Machado Castillo \& Tornes Olivera (2019), advierten la importancia de contar con un plan de negocios innovador que observe los diversos momentos de riestos que puede tener la producción para gestionar anticipatoriamente las estrategias pertinentes a focalizar las amenazas y abordar sinergicamente la vision de trabajo en consolidación de la empresa en el mediano y largo plazo.

\section{Tipos de Planes de Negocios Innovadores}

Los planes de negocios innovadores se muestran como una guía de las actividades puestas en marcha para el progreso de la empresa, también responden a necesidades que puede tener una empresa o un empresario con el objetivo de brindar información oportuna para el inversionista o accionista. Se explican los diferentes tipos:

Plan de negocios innovador para empresa en marcha; el objetivo es incrementar las unidades de negocio con el fin de ser mas rentables, lo ideal es hacer un analisis independiente enfocado solo a la nueva unidad de negocio, distribuyendo todos los costos de la empresa hacia todas las unidades de negocio incluyendo a la nueva unidad de negocio, además de mostrar un analisis FODA de la nueva unidad de negocio.

Plan de negocios innovador para nuevas empresas; se le considera como una herramienta inicial de diseño y parte de la idea del negocio a la cúal se la debe ir dando forma detallando la descripción de la idea, los objetivos, estrategías y acciones para alcanzar la meta. (Montero, Erazo, Narváez y Ormaza, 2019)

Plan de negocios innovador para inversionistas; a más de la información necesaria sobre la idea de negocio o puesta en marcha de la empresa, el plan debe contener datos relevantes sobre la factibilidad financiera, retorno de la inversión de manera que el inversionista este en la capacidad de apostar por la idea propuesta (Weinberger,2009). 
Plan de negocios de expansión; ampliar el negocio resulta interesante, esto indica que el negocio va bien y esta listo para crecer al siguiente nivel. Este plan va de la mano del apoyo financiero que determina la puesta en práctica las ideas de expansión. Se puede incluir diversos aspectos y cada empresa lo puede personalizar de acuerdo a la representatividad de la misma (INFOCIF, 2015).

En la empresa Transnexos, se manejará en base al tipo plan de negocios de expansión teniendo en cuenta las características propias de la empresa.

\section{Estructura del Plan de Negocios de Expansión}

No existe una estructura definitiva para armar el plan de negocios de expansión, por lo que cada empresario debería adaptar los componentes de acuerdo con las necesidades de la empresa. Por lo que se plantea lo siguiente:

1.- Descripción General: se hace una breve descripción de la empresa fijada en la determinación de la visión refiriéndose a lo que la empresa quiere ser en el futuro, misión se refiere a la razón de ser de la empresa y objetivos estratégicos los mismos deben cumplir con tres condiciones: que se establezcan para toda la organización, que se establezcan de manera permanente y que se establezcan en términos cuantitativos.

2.- Diagnostico Situacional: debe considerar las variables que pudieran representar las fortalezas, oportunidades, debilidades y amenazas (FODA). A través de este análisis el empresario podrá estar en la posición de determinar que fortalezas y debilidades ayudarán, para aprovechar las oportunidades y vencer las amenazas que puedan presentarse.

3.- Estudio de Mercado: determina considerar lo siguiente para el correcto analisis de mercado: a) descripción de producto o servicio, detallando sus caracteristicas, diseño, bondades, calidad, cantidad, disponibilidad, atributos. b) determinación de precio, se debe fijar en función a la estructura de costos de la empresa o a los precios de la competencia. c) distribución o plaza, se debe analizar cuales serán los canales de distribución sin dejar de lado el analisis de los costos que incurrira y evaluar si es conveniente o no. d) promoción, dar a conocer al mercado objetivo las bondades del 
producto o servicio. e) servicio al cliente o postventa, la diferenciación entre ellos se dará en el ámbito de los servicios de pre y postventa. f) posicionamiento, se trata de una diferenciación de los demás productos o servicios, este atributo debe ser significativo que pueda ser reconocido facilmente por el público objetivo (Weinberger, 2009).

4.- Proyecciones Financieras: deberá reflejar todas las decisiones que usted ha tomado a lo largo de su desarrollo. Por ejemplo, si usted decidió introducir un nuevo producto, desarrollar un nuevo mercado, contratar más personal, desarrollar actividades de integración que contribuyan a retener a sus trabajadores, comprar mayores inventarios de materia prima para evitar desabastecimientos, comprar nuevas maquinarias, hacer más publicidad o hacer mayores ofertas o descuentos para captar una mayor porción del mercado, todas esas decisiones tendrán un impacto en sus estados financieros. (Weinberger, 2009, p.93)

Después de realizar un análisis de los ingresos, costos y gastos de operación para la nueva unidad de negocio se debe realizar un presupuesto de inversión inicial, donde se debe incluir todo lo necesario para iniciar las operaciones del negocio como activos tangibles e intangibles.

El capital de trabajo se considera un recurso económico adicional, diferente al de la inversión inicial y sirve para financiar los primeros gastos o costos antes de percibir los ingresos por la venta del bien o servicio. Las fuentes de financiamiento se identifican mediante préstamos personales o familiares, financiamiento de terceros sea proveniente de los proveedores, financiamiento del sistema bancario mediante créditos y ayuda del estado.

El análisis de rentabilidad, se la expresa como una tasa en donde se espera que el dinero invertido le rente al empresario. Por lo que se debe considerar los índices: TIR y VAN. La elaboración de los estados financieros, considerados para el análisis y toma de decisiones oportunas deben ser el estado de resultados, flujo de caja y balance general (Weinberger, 2009).

5.- Plan de Acción: una vez determinados los objetivos a conseguir, se analiza cada una de las herramientas planteadas como: estrategias de marketing, ampliación o 
modificación de instalaciones, adquisición de maquinaria, vehículos o herramientas, con los que se valdría la empresa para alcanzar la expansión del negocio (INFOCIF, 2015).

\section{METODOLOGÍA}

El tipo de investigación que se aplicó es mixto (Cuali-cuantitativo), analizando la situación actual de cada uno de los procesos del servicio de transporte. Según el alcance, se utilizó la investigación descriptiva - explicativa con el fin de pretender e identificar las características y rasgos importantes.

Se utilizó el método histórico-lógico, para levantar la información real de la empresa con el fin de conocer la situación existente de ciertas tareas que involucran la prestación del servicio. Con el método analítico-sintético se pudo analizar algunas situaciones que afectan de manera directa a la línea de resultados. También el método inductivodeductivo ayudó para levantar información con respecto a la elaboración y entrega de los estados de resultados por parte del departamento contable. Se desarrolló el plan de negocios de expansión a través de un modelo, analizando todos los procesos considerados para el desarrollo de la empresa.

Se realizó una visita al Gerente General y a la Contadora, efectuando una guía de observación para levantar información de objetivos que se requieran ser considerados para el desarrollo de la empresa. Se ejecutaron encuestas a los clientes, los mismos respondieron a un cuestionario que contenía preguntas de interés y permitió recolectar datos de importancia para el desarrollo de la investigación. Finalmente se elaboró una entrevista al Gerente General y Jefe de Transporte, respondiendo interrogantes que permitió aportar con ideas y mejoras para el proceso del desarrollo de la empresa.

\section{RESULTADOS}

Los resultados de la investigación de campo se verán reflejados más adelante en el análisis de mercado.

A continuación, se presenta el esquema del plan de negocios de expansión. 


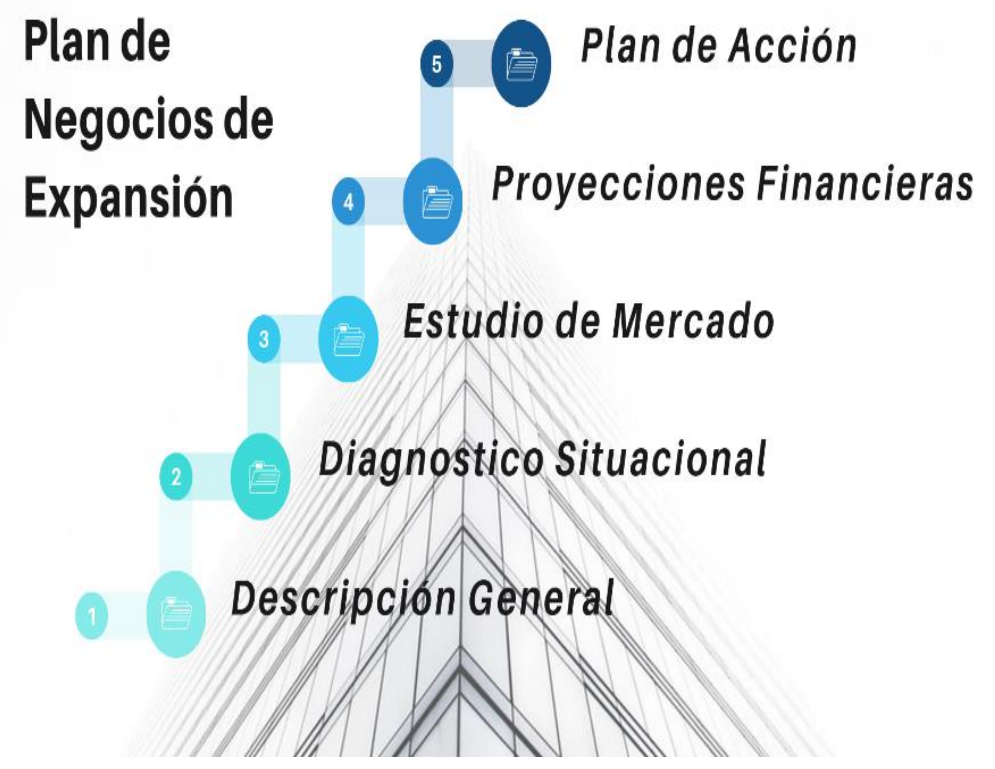

Figura 2. Esquema Propuesto Plan de Negocio de Expansión

\section{Descripción General}

A continuación, se presenta el nombre y logo de la empresa Transnexos por el que va a ser identificado por los clientes.

\section{Nombre y Logotipo}

La empresa está registrada en el Servicio de Rentas Internas (SRI) con los siguientes datos:

\section{Nombre Comercial: TRANSNEXOS S.A.}

RUC: 0190376982001

Actividad: actividades de transporte de carga pesada, combustible y gas natural licuado por carretera.

Fecha de inicio de actividades: 26/07/2011 


\section{Logotipo:}

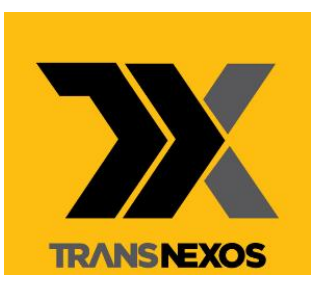

\section{Producto}

En la figura 3 se describen los servicios que ofrece la empresa Transnexos enfocados en la estrategia de expansión:

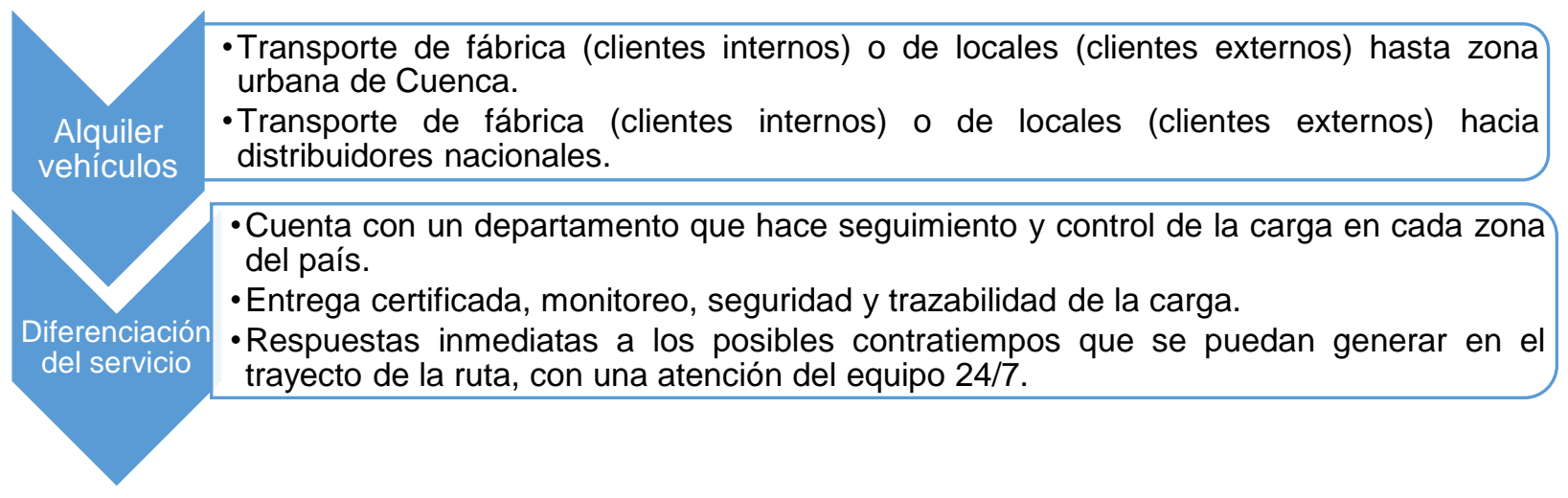

Figura 3. Descripción del servicio.

La empresa Transnexos busca expandir su negocio, con la integración y consolidación de los servicios para la movilidad de carga. En la figura 4 se explica la planeación estratégica planteada: 


\section{Misión}

- Entrega a nuestros clientes una solución integral a las necesidades de movilidad en toda la cadena de valor de la industria manufacturera comercial, de forma eficiente, con personal capacitado y herramientas de vanguardia que garanticen las operaciones a un costo óptimo, maximizando la satisfacción de nuestros clientes, comprometidos con la innovación, la optimización de los recursos y la creación de valor empresarial compartida.

\section{Visión}

- Ser una empresa de transporte que tenga estrategias de expansión en los servicios de movilidad de carga a nivel nacional, creando valor y satisfacción para nuestros clientes, contando con procesos estandarizados, infraestructura y tecnología.

\section{Objetivos}

- Analizar, organizar y optimizar las rutas logrando ágiles tiempos de respuesta.

- Seguimiento paso a paso de la ubicación excta de la carga.

- Adaptabilidad de horario con el cliente para la movilidad de la carga.

- Cobertura a nivel nacional.

\section{Valores}

- Lealtad

- Trabajo en equipo

- Justicia

- Transparencia

- Responsabilidad

- Seguridad

\section{Servicios y Ventajas}

- Coordinar con una sola entidad el servicio de movilidad de carga.

- Seguridad y trazabilidad de la operación.

- Almacenamiento de carga en bodegas situadas en puntos estratégicos.

- Reducción de costos logísticos al integrar las operaciones.

- Entrega ceritifcada.

- Disposición del equipo logístico.

Figura 4. Planeación estratégica 


\section{Diagnostico Situacional}

\section{Se desarrolló la matriz FODA para poder estimar las fortalezas y oportunidades que tiene la empresa y pueda solventar las amenazas y debilidades mediante definición de estrategias para cada fase.}

\begin{tabular}{|c|c|c|c|c|}
\hline Factores & Peso & Calificación & $\begin{array}{l}\text { Calificación } \\
\text { ponderada }\end{array}$ & Estrategias \\
\hline Debilidades & $50 \%$ & & & \\
\hline 1.- Cuenta con 17 tipos de vehículos para la movilidad de carga & 0.08 & 3 & 0.24 & $\begin{array}{l}\text { Desarrollar la estrategia de inversión de cuantos } \\
\text { vehículos se necesitan adquirir para cubrir rutas } \\
\text { para clientes externos }\end{array}$ \\
\hline $\begin{array}{l}\text { 2.- Brinda el servicio de transporte con una gran participación } \\
(99 \%) \text { solo a las empresas del GIG }\end{array}$ & 0.12 & 3 & 0.36 & $\begin{array}{l}\text { Elaborar un plan de expansión desarrollando los } \\
\text { componentes necesarios para incrementar clientes } \\
\text { externos }\end{array}$ \\
\hline $\begin{array}{l}\text { 3.- Falta de comunicación en los procesos de la operación del } \\
\text { servicio de transporte }\end{array}$ & 0.09 & 2 & 0.18 & $\begin{array}{l}\text { Desarrollar la Gestión por procesos determinando } \\
\text { las actividades en forma ordenada y controlada } \\
\text { mediante flujogramas }\end{array}$ \\
\hline $\begin{array}{l}\text { 4.- No cuenta con un plan de marketing para dar a conocer } \\
\text { sobre la empresa a clientes externos o potenciales }\end{array}$ & 0.09 & 2 & 0.18 & $\begin{array}{l}\text { Elaborar una estrategia de marketing para dar a } \\
\text { conocer los servicios que brinda la empresa a los } \\
\text { clientes externos }\end{array}$ \\
\hline $\begin{array}{l}\text { 5.- Los recursos financieros que genera la empresa no permiten } \\
\text { realizar inversiones para vehículos nuevos }\end{array}$ & 0.11 & 3 & 0.33 & $\begin{array}{l}\text { Evaluar la estructura de costos operativos para } \\
\text { poder optimizar de acuerdo a la ruta que sea } \\
\text { menos rentable, de manera de incrementar los } \\
\text { resultados financieros }\end{array}$ \\
\hline Fortalezas & $50 \%$ & & & \\
\hline $\begin{array}{l}\text { 1.- Atender las necesidades de movilidad de carga para la } \\
\text { industria manufacturera y comercial }\end{array}$ & 0.08 & 4 & 0.32 & $\begin{array}{l}\text { Realizar un análisis de rutas en donde indique la } \\
\text { rentabilidad de cada una, de manera que se pueda } \\
\text { cubrir el servicio a nivel nacional }\end{array}$ \\
\hline $\begin{array}{l}\text { 2.- Cuenta con transportistas debidamente calificados y } \\
\text { certificados }\end{array}$ & 0.09 & 3 & 0.27 & $\begin{array}{l}\text { Tener un plan de capacitación para los } \\
\text { transportistas en lo que refiere a leyes de tránsito, } \\
\text { normas y alcances en la tecnología de los } \\
\text { vehículos }\end{array}$ \\
\hline $\begin{array}{l}\text { 3.- Almacenamiento de la carga en bodegas situadas en puntos } \\
\text { estratégicos del país }\end{array}$ & 0.08 & 4 & 0.32 & $\begin{array}{l}\text { Plan de seguimiento y seguridad de la carga } \\
\text { almacenando en las bodegas, con esto se evitan } \\
\text { viajes innecesarios }\end{array}$ \\
\hline $\begin{array}{l}\text { 4.- Fácil comunicación con los departamentos responsables de } \\
\text { los clientes internos para los envíos }\end{array}$ & 0.09 & 4 & 0.36 & $\begin{array}{l}\text { Disposición del equipo logístico para atender los } \\
\text { requerimientos de los clientes }\end{array}$ \\
\hline $\begin{array}{l}\text { 5.- La empresa tiene horarios accesibles para atender los } \\
\text { requerimientos de sus clientes }\end{array}$ & 0.07 & 3 & 0.21 & $\begin{array}{l}\text { Adaptabilidad al horario del cliente con ágiles } \\
\text { respuestas para cubrir la ruta requerida por el } \\
\text { cliente }\end{array}$ \\
\hline
\end{tabular}


Revista Arbitrada Interdisciplinaria KOINONIA

Año IV. Vol IV. N¹. Edición Especial 2019

Hecho el depósito de Ley: FA2016000010

ISSN: $2542-3088$

FUNDACIÓN KOINONIA (F.K). Santa Ana de Coro. Venezuela.

Jhoana Alexandra Picón Vizhñay; Juan Carlos Erazo Álvarez; Cecilia Ivonne Narváez Zurita

\begin{tabular}{|c|c|c|c|c|}
\hline Factores & Peso & Calificación & $\begin{array}{l}\text { Calificación } \\
\text { ponderada }\end{array}$ & Estrategias \\
\hline Amenazas & $50 \%$ & & & \\
\hline 1.- Gremios asociados que regulan precios & 0.09 & 2 & 0.18 & $\begin{array}{l}\text { Estrategia de precios considerando la optimización } \\
\text { costos de operación y la ruta }\end{array}$ \\
\hline 2.- Gran número de empresas de transporte similares & 0.12 & 3 & 0.36 & $\begin{array}{l}\text { Realizar un estudio de mercado en el que se } \\
\text { identifique la competencia directa para la empresa }\end{array}$ \\
\hline 3.- Desastres climáticos o naturales que estropeen carreteras & 0.09 & 2 & 0.18 & $\begin{array}{l}\text { Evaluar los estados de los vehículos con el fin que } \\
\text { puedan sobrepasar un daño en la carretera y poder } \\
\text { brindar el servicio a los clientes internos y externos }\end{array}$ \\
\hline $\begin{array}{l}\text { 4.- Elevación de impuestos y aranceles al momento de importar } \\
\text { repuestos para los vehículos }\end{array}$ & 0.09 & 2 & 0.18 & $\begin{array}{l}\text { Realizar un plan correctivo para el mantenimiento } \\
\text { de vehículos de manera que se pueda cronometrar } \\
\text { el pedido de repuestos que sean importados y } \\
\text { evitar los altos impuestos }\end{array}$ \\
\hline 5.- Cambios de políticas del gobierno actual & 0.09 & 2 & 0.18 & $\begin{array}{l}\text { Tener al equipo logístico al tanto de los cambios } \\
\text { para evitar costos innecesarios }\end{array}$ \\
\hline Oportunidades & $50 \%$ & & & \\
\hline 2.- Gobierno cuenta con $9.998 \mathrm{~km}$ pavimentados & 0.09 & 3 & 0.27 & $\begin{array}{l}\text { Optimización de tiempos de entregas de la carga a } \\
\text { los clientes con mejores carreteras }\end{array}$ \\
\hline $\begin{array}{l}\text { 3.- La comunicación se la realiza mediante correos electrónicos } \\
\text { y mensajes whatsAap }\end{array}$ & 0.08 & 4 & 0.32 & $\begin{array}{l}\text { Realizar un plan de comunicación mediante las } \\
\text { redes sociales en donde se dé a conocer los } \\
\text { servicios de la empresa para los clientes internos y } \\
\text { externos }\end{array}$ \\
\hline 4.- Planes de financiamiento para inversión & 0.09 & 4 & 0.36 & $\begin{array}{l}\text { Evaluar un plan de financiamiento con una entidad } \\
\text { financiera obteniendo una tasa de interés acorde, } \\
\text { que permita realizar inversiones }\end{array}$ \\
\hline 5.- Rutas accesibles a nivel nacional & 0.07 & 3 & 0.21 & $\begin{array}{l}\text { Evaluación del estado de los vehículos que estén } \\
\text { prestos a cubrir la movilidad de carga de los } \\
\text { clientes en todas las rutas a nivel nacional }\end{array}$ \\
\hline $\begin{array}{ll}\text { Totales } \\
\end{array}$ & $100 \%$ & & 2.72 & \\
\hline
\end{tabular}

\section{Estudio de Mercado}

\section{Oferta}

La competencia directa de la empresa Transnexos se encuentran en otras operadoras logísticas del país y en las empresas de transporte de carga. En la tabla 3 se adjuntan las empresas de transporte de carga que operan en la ciudad de Cuenca y las operadoras logísticas registradas en el país, que se consideran competencia directa para la empresa. 


\section{Tabla 4}

Detalle de empresas de transporte de carga y operadoras logísticas

Nombre

Transporte de carga Semeria

ENETSA

Transportes Ortiz S.A.

Transportes Mobachs Cuenca Cía. Ltda.

Transporte CICAPSUR S.A.

Gaviota Express

Empresa de Transporte Baculimatrans S.A.

MATCOYCAPE S.A.

CAVIAC S.A.

Transporte Serviazuay S.A.

Compañía de Transp. BRYSEAR CARGO S.A.

Tran Sur

Viajeros Internacional

Transporte Miriumi S.A.

Trans Teresita

Blue Target

Trancisne Cía. Ltda.

Cooperativa Santa Encomiendas

Trans. Méndez

Trans. Narváez Cía. Ltda.

Gescotrans

Transemil

López Express e Hijos Cía. Ltda.

\begin{tabular}{|c|c|c|}
\hline Dirección & Teléfono & \\
\hline Av. Hurtado de Mendoza & $\begin{array}{l}(07) 287- \\
1022 \\
(07) 280- \\
2999\end{array}$ & \\
\hline Calle Huacas & $\begin{array}{l}(07) 408- \\
7951\end{array}$ & \\
\hline Calle del Batán & $\begin{array}{l}099 \\
8822\end{array}$ & 845 \\
\hline Altiplano & $\begin{array}{l}(07) 417- \\
3085 \\
099 \\
4037\end{array}$ & 735 \\
\hline Camino viejo a Baños & $\begin{array}{l}(07) 405- \\
4081 \\
099 \\
5100\end{array}$ & 145 \\
\hline El Consorcio 101 & $\begin{array}{l}(07) 287- \\
1647\end{array}$ & \\
\hline Ramona Cordero y León & $\begin{array}{l}(07) 285- \\
5529\end{array}$ & \\
\hline & $\begin{array}{l}099 \\
8457\end{array}$ & 380 \\
\hline Edwin Sacoto & $\begin{array}{l}099 \\
6994\end{array}$ & 712 \\
\hline Av. España & $\begin{array}{l}(07) 287- \\
7938\end{array}$ & \\
\hline Calle Vieja & $\begin{array}{l}(07) 411- \\
0403\end{array}$ & \\
\hline & $\begin{array}{l}096 \\
7547\end{array}$ & 944 \\
\hline Calle Cantón Paute & $\begin{array}{l}(07) 240- \\
4671\end{array}$ & \\
\hline La Feria & $\begin{array}{l}(07) 285- \\
4068 \\
(07) 286- \\
8399\end{array}$ & \\
\hline Del Pasacalle & $\begin{array}{l}(07) 284- \\
9258\end{array}$ & \\
\hline Carlos Arizaga Vega & $\begin{array}{l}(07) 285- \\
4773\end{array}$ & \\
\hline De Las Pencas & $\begin{array}{l}(07) 285- \\
8900\end{array}$ & \\
\hline Cristo del Consuelo & $\begin{array}{l}(07) 410- \\
0235\end{array}$ & \\
\hline
\end{tabular}


Translod S.A.

Transporte Yanzaoriente

Camiones Megatrans

Carga Austral S.A.

Flex.net Operador Logístico

VIR Operador Logístico
099

6478

Saraurco

Av. De Las Américas

(07)286-

5584

099

9093

Av. Ordoñez Lasso

(07)419-

3551

Quito

(02)202-

2570

Quito-Guayaquil

(04)372-
808

6-

755 6230

\section{Demanda}

Como estrategia de expansión del negocio se determinó incrementar el número de clientes externos del (GIG), de manera que se define la siguiente población:

1) El $N^{\circ}$ de clientes internos, se consideraron las empresas del (GIG), siendo los solicitantes del servicio los trabajadores de los departamentos de tráfico y distribución de producto terminado y los que coordinan la entrega de materia prima.

2) El $\mathrm{N}^{\circ}$ clientes externos, se consideró los clientes de las empresas Graiman y Tubería Galvanizada que forman parte del (GIG), que corresponden a la ciudad de Cuenca y están creados en la base de la empresa como distribuidores, constructores y ferreteros que tengan un local comercial, para ello se solicitó la base de clientes de estas empresas. Se consideró estas dos empresas, debido a que se revisó las ventas del primer trimestre de la empresa Transnexos del año 2019 y se encontró que un 93\% corresponde a facturaciones que se han hecho a Graiman y Tubería Galvanizada. Esto dio como indicador para poder buscar clientes externos en estas empresas. 


\section{Tabla 5}

Tamaño de la muestra

\begin{tabular}{lcl} 
Variables & $\begin{array}{l}\text { Muestra } \\
\text { (habitantes) }\end{array}$ & Tipo \\
\hline Trabajadores & 2 & Entrevista \\
Transnexos & 12 & Encuesta \\
Clientes Internos GIG & 20 & Encuesta \\
Clientes Externos & $\mathbf{3 4}$ & \\
Total & & \\
\hline
\end{tabular}

Fuente: Trabajo de investigación de campo

\section{Cuantificación de la demanda}

Se realizó el análisis del cuestionario a los clientes internos y externos de la empresa Transnexos, se adjunta el análisis de las preguntas de interés con respecto a la propuesta de incrementar la rentabilidad.

\section{Medición de la frecuencia de envíos mensuales}

De la encuesta aplicada a los clientes internos y externos, se obtuvo que el $44 \%$ de la población encuestada indico que el número de veces que envían sus productos o materiales por una empresa de transporte es más de 10 veces al mes, otro 44\% envía de 1 a 5 veces al mes y un 13\% envía de 6 a 10 veces al mes.

\section{Medición del lugar de destino a enviar}

De acuerdo con la encuesta aplicada, se evidencia que el $25 \%$ de la población encuestada indico que sus productos o materiales envían con más frecuencia a otras ciudades como: Loja, Machala, Santo Domingo, Azogues; el 20\% envía a Guayaquil; un 17\% envía a Quito; un 13\% envía a Ambato; un 7\% envía a Riobamba; quedando un 18\% que indicaron que envían al restante de lugares que se enlistaron en el cuestionario.

\section{Medición de la comunicación}

Del total de clientes internos y externos encuestados, el $48 \%$ indicó que se comunica con la empresa de transporte mediante recomendaciones personales, seguido del $18 \%$ que se comunica mediante correo electrónico, un 8\% mediante extensión telefónica, un 7\% 
mediante la guía telefónica, un 5\% mediante WhatsApp y enlace empresarial, un $4 \%$ mediante una tarjeta de presentación, un $3 \%$ mediante otros medios como internet y un $1 \%$ acude a la oficina.

\section{Proyecciones Financieras}

En el análisis financiero se debe considerar todos los costos y gastos que involucran el desarrollo de las actividades de la empresa, incluyendo los costos de expansión del negocio, para el caso de Transnexos incrementar los clientes externos, de manera que se busque la optimización y se evidencien como mejora en los resultados financieros. Para ello se adjuntan los análisis de ingresos, costos y gastos operacionales para cada línea de ingreso.

Los estados financieros tienen una proyección para 5 años, con un \% incremental en ventas, costos y gastos operacionales de acuerdo con la variación de índice de precios al consumidor referido en los últimos seis años en los meses de julio:

\section{Tabla 6}

Variación Índice de Precios al Consumidor

Fuente: (INEC, 2019).

\begin{tabular}{ll} 
Año & Variación IPC \\
\hline jul-14 & 4.11 \\
jul-15 & 4.36 \\
jul-16 & 1.58 \\
jul-17 & 0.1 \\
jul-18 & -0.57 \\
jul-19 & 0.71 \\
Promedio & $\mathbf{1 . 7 2 \%}$ \\
\hline
\end{tabular}

\section{Estimación de los Ingresos}

Para estimar los ingresos de los clientes externos se consideró la frecuencia de envíos mensuales a los destinos de preferencia, considerando las toneladas enviadas de acuerdo con la capacidad que tienen los vehículos y el precio estimado por la empresa Transnexos el mismo está regulado por el mercado. 


\section{Tabla 7}

Desglose de ingresos mensuales clientes externos

\begin{tabular}{lcccc} 
Destino & $\mathbf{N}^{\circ}$ de envíos al mes & Capacidad TN enviada & Precio TN & USD mensual \\
\hline Quito & 72 & 15 & 22.00 & 23,760 \\
Guayaquil & 88 & 15 & 10.30 & 13,596 \\
Ambato & 72 & 15 & 20.50 & 22,140 \\
La Troncal & 8 & 15 & 10.30 & 1,236 \\
Milagro & 8 & 15 & 10.30 & 1,236 \\
Portoviejo & 32 & 15 & 22.50 & 10,800 \\
Manta & 24 & 15 & 22.50 & 8,100 \\
Babahoyo & 16 & 15 & 12.50 & 3,000 \\
Riobamba & 40 & 15 & 20.50 & 12,300 \\
lbarra & 8 & 15 & 10.30 & 1,236 \\
Puyo & 8 & 15 & 25.90 & 3,108 \\
Loja & 40 & 15 & 16.00 & 9,600 \\
Quevedo & 8 & 15 & 20.50 & 2,460 \\
Machala & 16 & 15 & 14.00 & 3,360 \\
Interno Cuenca & 16 & 15 & 2.22 & 533 \\
TOTAL & $\mathbf{4 5 6}$ & $\mathbf{2 2 5}$ & & $\mathbf{1 1 6 , 4 6 5}$ \\
\hline
\end{tabular}

Fuente: Empresa Transnexos, 2019.

\section{Costos Operativos}

\section{Tabla 8}

Detalle de costos operativos clientes internos

\begin{tabular}{lr} 
Costo Operativo Clientes Internos & $\mathbf{2 0 2 0}$ proyectado \\
\cline { 2 - 2 } Variables & $\mathbf{1 , 3 8 6 , \mathbf { 1 7 3 }}$ \\
Mantenimiento y Rep. Vehículos & $\mathbf{7 1 1 , 5 3 2}$ \\
Combustibles & 431,523 \\
Alquiler renting / Neumáticos & 212,793 \\
Viáticos & 20,039 \\
Fijos & 47,177 \\
Mano de Obra & $\mathbf{6 7 4 , 6 4 1}$ \\
Depreciación & 227,862 \\
Seguros & 205,984 \\
Horas extras & 85,224 \\
Servicios Prestados y Honorarios & 79,072 \\
Matriculas & 42,310 \\
Alquiler maquinaria & 20,351 \\
Teléfonos y comunicaciones & 7,142 \\
Útiles de Oficina & 4,907 \\
\hline
\end{tabular}

Fuente: Empresa Transnexos, 2019. 


\section{Tabla 8}

Detalle de costos operativos clientes externos

\begin{tabular}{lr} 
& $\mathbf{2 0 2 0}$ \\
proyectado \\
Costo Operativo Clientes Externos & $\mathbf{8 6 3 , 6 7 5}$ \\
\hline Variables & $\mathbf{5 5 9 , 9 6 3}$ \\
Mantenimiento y Rep. Vehículos & 183,306 \\
Combustibles & 286,241 \\
Alquiler renting / Neumáticos & 26,955 \\
Viáticos & 63,461 \\
Fijos & $\mathbf{3 0 3 , 7 1 2}$ \\
Mano de Obra & 96,774 \\
Depreciación & 84,018 \\
Seguros & 47,625 \\
Horas extras & 33,582 \\
Servicios Prestados y Honorarios & 23,644 \\
Matriculas & 11,373 \\
Teléfonos y comunicaciones & 4,907 \\
Útiles de Oficina & 1,789 \\
\hline
\end{tabular}

Fuente: Empresa Transnexos, 2019. 


\section{Gastos Operacionales}

\section{Tabla 10}

Detalle de gastos operacionales

\begin{tabular}{lr} 
Gastos Operacionales & $\mathbf{3 8 2 , 1 2 5}$ \\
\hline Gastos Administrativos & $\mathbf{2 7 1 , 1 9 7}$ \\
Nómina & 172,007 \\
Gastos del personal & 43,943 \\
Jubilación patronal y Desahucio & 40,265 \\
Honorarios y Servicios Prestados & 7,032 \\
Alquiler renting/Vehículos livianos & 7,950 \\
Gastos de Ventas & \\
Gastos de personal & 65,819 \\
Gastos de comunicación & 36,774 \\
Alquiler renting/Vehículos livianos & 10,100 \\
Honorarios y Servicios Prestados & 11,763 \\
Impuestos y Contribuciones & 3,952 \\
& 3,230 \\
Gastos Corporativos & \\
Nómina & $\mathbf{4 5 , 1 1 0}$ \\
Gastos de personal & 34,544 \\
Honorarios y Servicios Prestados & 8,716 \\
\hline
\end{tabular}

Fuente: Empresa Transnexos, 2019.

2020 proyectado 382,125

172,007

4,943

7,032

65,819

36,774

11,763

3,952

3,230

45,110

34,544

1,850

Con la consolidación de los costos y gastos operativos se procedió a preparar los estados financieros:

- El estado de pérdidas y ganancias para el período 2019, se estructura considerando las ventas reales de enero a julio y se estima una proyección para los meses agosto a diciembre en base al primer semestre, para el período 2020 se muestra la expansión de la línea para clientes externos, de manera que se pueda evidenciar el incremento en la rentabilidad que se esperaría obtener.

- El balance general considera los valores reales hasta el mes de julio 2019, partiendo como base para la proyección para el período 2020. 


\section{- El flujo de caja se elaboró en base a las necesidades de la empresa considerando el valor de la inversión y el financiamiento requerido.}

\section{Tabla 11}

\section{Estado de Resultados Proyectado para la empresa Transnexos}

\begin{tabular}{|c|c|c|c|c|c|c|c|c|c|c|c|c|}
\hline & \multicolumn{2}{|l|}{0} & \multicolumn{2}{|l|}{1} & \multicolumn{2}{|l|}{2} & \multicolumn{2}{|l|}{3} & \multicolumn{2}{|l|}{4} & \multicolumn{2}{|l|}{5} \\
\hline & 2019 & AV & 2020 & AV & 2021 & AV & 2022 & AV & 2023 & AV & 2024 & AV \\
\hline Ventas & $1,907,132$ & $100 \%$ & $3,282,876$ & $100 \%$ & $3,339,178$ & $100 \%$ & $3,396,444$ & $100 \%$ & $3,454,693$ & $100 \%$ & $3,513,941$ & $100 \%$ \\
\hline Transporte Clientes internos & $1,885,299$ & $99 \%$ & $1,885,299$ & $57 \%$ & $1,917,631$ & $57 \%$ & $1,950,519$ & $57 \%$ & $1,983,970$ & $57 \%$ & $2,017,995$ & $57 \%$ \\
\hline Transporte Clientes externos & 21,833 & $1 \%$ & $1,397,578$ & $43 \%$ & $1,421,546$ & $43 \%$ & $1,445,926$ & $43 \%$ & $1,470,723$ & $43 \%$ & $1,495,946$ & $43 \%$ \\
\hline Costo de Ventas & $1,402,226$ & $74 \%$ & $2,249,849$ & $69 \%$ & $2,288,434$ & $69 \%$ & $2,327,680$ & $69 \%$ & $2,367,600$ & $69 \%$ & $2,408,204$ & $69 \%$ \\
\hline Transporte Clientes internos & $1,386,173$ & $74 \%$ & $1,386,173$ & $74 \%$ & $1,409,946$ & $74 \%$ & $1,434,127$ & $74 \%$ & $1,458,722$ & $74 \%$ & $1,483,739$ & $74 \%$ \\
\hline Transporte Clientes externos & 16,053 & $74 \%$ & 863,675 & $62 \%$ & 878,487 & $62 \%$ & 893,553 & $62 \%$ & 908,878 & $62 \%$ & 924,465 & $62 \%$ \\
\hline Utilidad Bruta & 504,905 & $26 \%$ & $1,033,027$ & $31 \%$ & $1,050,744$ & $31 \%$ & $1,068,764$ & $31 \%$ & $1,087,093$ & $31 \%$ & $1,105,737$ & $31 \%$ \\
\hline Transporte Clientes internos & 499,125 & $26 \%$ & 499,125 & $26 \%$ & 507,685 & $26 \%$ & 516,392 & $26 \%$ & 525,248 & $26 \%$ & 534,256 & $26 \%$ \\
\hline Transporte Clientes externos & 5,780 & $26 \%$ & 533,902 & $38 \%$ & 543,059 & $38 \%$ & 552,372 & $38 \%$ & 561,845 & $38 \%$ & 571,481 & $38 \%$ \\
\hline Gastos Operacionales & 387,820 & $20 \%$ & 382,125 & $12 \%$ & 388,678 & $12 \%$ & 395,344 & $12 \%$ & 402,124 & $12 \%$ & 409,021 & $12 \%$ \\
\hline Gastos Administración & 273,663 & $14 \%$ & 271,197 & $8 \%$ & 275,848 & $8 \%$ & 280,578 & $8 \%$ & 285,390 & $8 \%$ & 290,285 & $8 \%$ \\
\hline Gastos de Ventas & 68,582 & $4 \%$ & 65,819 & $2 \%$ & 66,947 & $2 \%$ & 68,096 & $2 \%$ & 69,263 & $2 \%$ & 70,451 & $2 \%$ \\
\hline Gastos Corporativos & 45,575 & $2 \%$ & 45,110 & $1 \%$ & 45,883 & $1 \%$ & 46,670 & $1 \%$ & 47,471 & $1 \%$ & 48,285 & $1 \%$ \\
\hline Utilidad Operacional & 117,086 & $6 \%$ & 650,902 & $20 \%$ & 662,065 & $20 \%$ & 673,420 & $20 \%$ & 684,969 & $20 \%$ & 696,716 & $20 \%$ \\
\hline Gastos Financieros & 12,034 & $1 \%$ & 101,836 & $3 \%$ & 94,507 & $3 \%$ & 86,550 & $3 \%$ & 77,911 & $2 \%$ & 68,532 & $2 \%$ \\
\hline Otros Ingresos y Egresos & 32,166 & $2 \%$ & - & $0 \%$ & - & $0 \%$ & - & $0 \%$ & - & $0 \%$ & - & $0 \%$ \\
\hline Otros Ingresos & 37,974 & $2 \%$ & - & $0 \%$ & - & $0 \%$ & - & $0 \%$ & - & $0 \%$ & - & $0 \%$ \\
\hline Otros Egresos & $-5,808$ & $0 \%$ & - & $0 \%$ & - & $0 \%$ & - & $0 \%$ & - & $0 \%$ & - & $0 \%$ \\
\hline Utilidad antes de impuestos & 137,217 & $7 \%$ & 549,066 & $17 \%$ & 567,558 & $17 \%$ & 586,870 & $17 \%$ & 607,058 & $18 \%$ & 628,184 & $18 \%$ \\
\hline
\end{tabular}

Fuente: Empresa Transnexos, 2019. 


\section{Tabla 12}

\section{Balance General Proyectado para la empresa Transnexos}

\begin{tabular}{|c|c|c|c|c|c|c|}
\hline & & & & & & \\
\hline & 0 & 1 & 2 & 3 & 4 & 5 \\
\hline & 2019 & 2020 & 2021 & 2022 & 2023 & 2024 \\
\hline \multicolumn{7}{|l|}{ Activos } \\
\hline \multicolumn{7}{|l|}{ Activos Corrientes } \\
\hline Efectivo y equivalentes de efectivo & 244,499 & $1,187,472$ & $1,094,616$ & 993,802 & $1,078,228$ & $1,450,197$ \\
\hline Cuentas por cobrar a clientes & 22,222 & 22,603 & 22,991 & 23,385 & 23,786 & 24,194 \\
\hline Cuentas por cobrar a compañias relacionadas & 439,110 & 446,641 & 454,301 & 462,092 & 470,017 & 478,078 \\
\hline Cuentas por cobrar a empleados & 442 & 449 & 457 & 465 & 473 & 481 \\
\hline Otras cuentas por cobrar & 25,378 & 25,813 & 26,256 & 26,706 & 27,164 & 27,630 \\
\hline Impuestos por recuperar & 13,340 & 13,569 & 13,802 & 14,038 & 14,279 & 14,524 \\
\hline Gastos pagados por anticipado & 55,994 & 56,955 & 57,932 & 58,925 & 59,936 & 60,964 \\
\hline Total activos corrientes & 800,985 & $1,753,503$ & $1,670,353$ & $1,579,413$ & $1,673,883$ & $2,056,068$ \\
\hline \multicolumn{7}{|l|}{ Activos no Corrientes } \\
\hline Propiedades, planta y equipos & $1,214,691$ & $2,132,394$ & $1,820,395$ & $1,508,395$ & $1,196,395$ & 884,395 \\
\hline Activos intangibles sujetos a amortización & 7,624 & 7,624 & 7,624 & 7,624 & 7,624 & 7,624 \\
\hline Total activos no corrientes & $1,222,314$ & $2,140,018$ & $1,828,018$ & $1,516,019$ & $1,204,019$ & 892,019 \\
\hline Total de activos & $2,023,300$ & $3,893,521$ & $3,498,372$ & $3,095,432$ & \begin{tabular}{|l|}
$2,877,902$ \\
\end{tabular} & $2,948,087$ \\
\hline \multicolumn{7}{|l|}{ Pasivos } \\
\hline \multicolumn{7}{|l|}{ Pasivo Corriente } \\
\hline Obligaciones bancarias $\mathrm{CP}$ & 72,222 & 140,528 & 92,857 & 100,814 & 109,453 & 118,832 \\
\hline Cuentas por pagar a proveedores & 82,492 & 83,907 & 85,346 & 86,810 & 88,299 & 89,813 \\
\hline Cuentas por pagar a compañías relacionadas & 280,700 & 285,514 & 290,410 & 295,391 & 300,457 & 305,610 \\
\hline Otros impuestos por pagar & 750 & 763 & 776 & 789 & 803 & 817 \\
\hline Otras cuentas por pagar & 6,699 & 6,814 & 6,931 & 7,050 & 7,170 & 7,293 \\
\hline Beneficios sociales a corto plazo & 48,507 & 49,339 & 50,186 & 51,046 & 51,922 & 52,812 \\
\hline Total del Pasivo Corriente & 491,371 & 566,865 & 526,505 & 541,899 & 558,103 & 575,177 \\
\hline \multicolumn{7}{|l|}{ Pasivo no Corriente } \\
\hline Obligaciones bancarias LP & 44,444 & $1,246,906$ & 852,907 & 394,188 & 118,832 & 129,015 \\
\hline Beneficios sociales LP & 209,046 & 212,631 & 216,278 & 219,987 & 223,760 & 227,597 \\
\hline Impuesto diferido & $-6,281$ & $-6,389$ & $-6,498$ & $-6,610$ & $-6,723$ & $-6,839$ \\
\hline Total del Pasivo No Corriente & 247,209 & $1,453,149$ & $1,062,686$ & 607,566 & 335,869 & 349,774 \\
\hline Total de Pasivo & 738,580 & $2,020,013$ & $1,589,192$ & $1,149,465$ & 893,972 & 924,950 \\
\hline \multicolumn{7}{|l|}{ Patrimonio } \\
\hline Capital Social & 984,900 & $1,001,791$ & $1,018,972$ & $1,036,447$ & $1,054,222$ & $1,072,302$ \\
\hline Reservas & 322,650 & 322,650 & 322,650 & 322,650 & 322,650 & 322,650 \\
\hline Resultados acumulados & $-80,106$ & & & & & \\
\hline Resultados del ejercicio & 57,275 & 549,066 & 567,558 & 586,870 & 607,058 & 628,184 \\
\hline Patrimonio Total & $1,284,719$ & $1,873,507$ & $1,909,180$ & $1,945,967$ & $1,983,930$ & $2,023,136$ \\
\hline Total Pasivo + Patrimonio & $2,023,300$ & $3,893,521$ & $3,498,372$ & $3,095,432$ & $2,877,902$ & $2,948,087$ \\
\hline
\end{tabular}

Fuente: Empresa Transnexos, 2019. 


\section{Tabla 13}

Flujo de Caja Proyectado para la empresa Transnexos

\begin{tabular}{|c|c|c|c|c|c|c|}
\hline & & & & & & \\
\hline & 0 & 1 & 2 & 3 & 4 & 5 \\
\hline & 2019 & 2020 & 2021 & 2022 & 2023 & 2024 \\
\hline Ventas & & $3,282,876$ & $3,339,178$ & $3,396,444$ & $3,454,693$ & $3,513,941$ \\
\hline Transporte Clientes internos & & $1,885,299$ & $1,917,631$ & $1,950,519$ & $1,983,970$ & $2,017,995$ \\
\hline Transporte Clientes externos & & $1,397,578$ & $1,421,546$ & $1,445,926$ & $1,470,723$ & $1,495,946$ \\
\hline Costo de Ventas & & $2,249,849$ & $2,288,434$ & $2,327,680$ & $2,367,600$ & $2,408,204$ \\
\hline Transporte Clientes internos & & $1,386,173$ & $1,409,946$ & $1,434,127$ & $1,458,722$ & $1,483,739$ \\
\hline Transporte Clientes externos & & 863,675 & 878,487 & 893,553 & 908,878 & 924,465 \\
\hline Utilidad Bruta & & $1,033,027$ & $1,050,744$ & $1,068,764$ & $1,087,093$ & $1,105,737$ \\
\hline Transporte Clientes internos & & 499,125 & 507,685 & 516,392 & 525,248 & 534,256 \\
\hline Transporte Clientes externos & & 533,902 & 543,059 & 552,372 & 561,845 & 571,481 \\
\hline Gastos Operacionales & & 382,125 & 388,678 & 395,344 & 402,124 & 409,021 \\
\hline Gastos Administración & & 271,197 & 275,848 & 280,578 & 285,390 & 290,285 \\
\hline Gastos de Ventas & & 65,819 & 66,947 & 68,096 & 69,263 & 70,451 \\
\hline Gastos Corporativos & & 45,110 & 45,883 & 46,670 & 47,471 & 48,285 \\
\hline Utilidad Operacional & & 650,902 & 662,065 & 673,420 & 684,969 & 696,716 \\
\hline Gastos Financieros & & 101,836 & 94,507 & 86,550 & 77,911 & 68,532 \\
\hline Otros Ingresos y Egresos & & - & - & - & - & - \\
\hline Utilidad antes de impuestos & & 549,066 & 567,558 & 586,870 & 607,058 & 628,184 \\
\hline Mas Gastos Depreciación & & 88,440 & 88,440 & 88,440 & 88,440 & 88,440 \\
\hline Menos Gastos Amortizaciones Deuda & & 85,528 & 92,857 & 100,814 & 109,453 & 118,832 \\
\hline Préstamo & $-1,273,000$ & & & & & \\
\hline Inversión inicial & $-1,273,000$ & & & & & \\
\hline Flujo neto efectivo & $-1,273,000$ & $-721,022$ & $-157,880$ & 416,615 & $1,002,660$ & $1,600,452$ \\
\hline
\end{tabular}

Fuente: Empresa Transnexos, 2019.

\section{Cálculo de VAN y TIR}

Con intención de verificar que tan factible es la estrategia de expansión de la línea de ingresos para los clientes externos en la empresa Transnexos, se hará uso del flujo de caja proyectado para poder determinar el VAN y TIR.

Para determinar la tasa mínima aceptable de rendimiento TMAR, se considera la tasa promedio de inflación siendo la variación del IPC 1.72\% y el riesgo de inversión medio estimando el 7\%, dado que se tiene una demanda limitada y una competencia alta. En la tabla 14 se evidencia los resultados obtenidos: 


\section{Tabla 14.}

Resultados VAN y TIR

\begin{tabular}{llll} 
TMAR & $8.72 \%$ & Riesgo de la inversión & $7.00 \%$ \\
\hline VAN (8.72\%) & $\$ 26,113.53$ & (+) Tasa de inflación (IPC) & $1.72 \%$ \\
TIR & $9.07 \%$ & $(=)$ TMAR & $8.72 \%$ \\
\hline
\end{tabular}

Siendo el TIR mayor que la TMAR y el VAN mayor que 0 se considera viable la expansión del negocio en la empresa Transnexos

\section{5.-Plan de Acción}

\section{Estrategias de Gestión Organizacional}

\section{División espacial}

Para el desarrollo de plan de expansión se requerirá adecuar organizacionalmente la superficie física, de manera que se mejora la productividad en cada uno de los procesos, en la figura 5 se presenta la división espacial para la empresa Transnexos

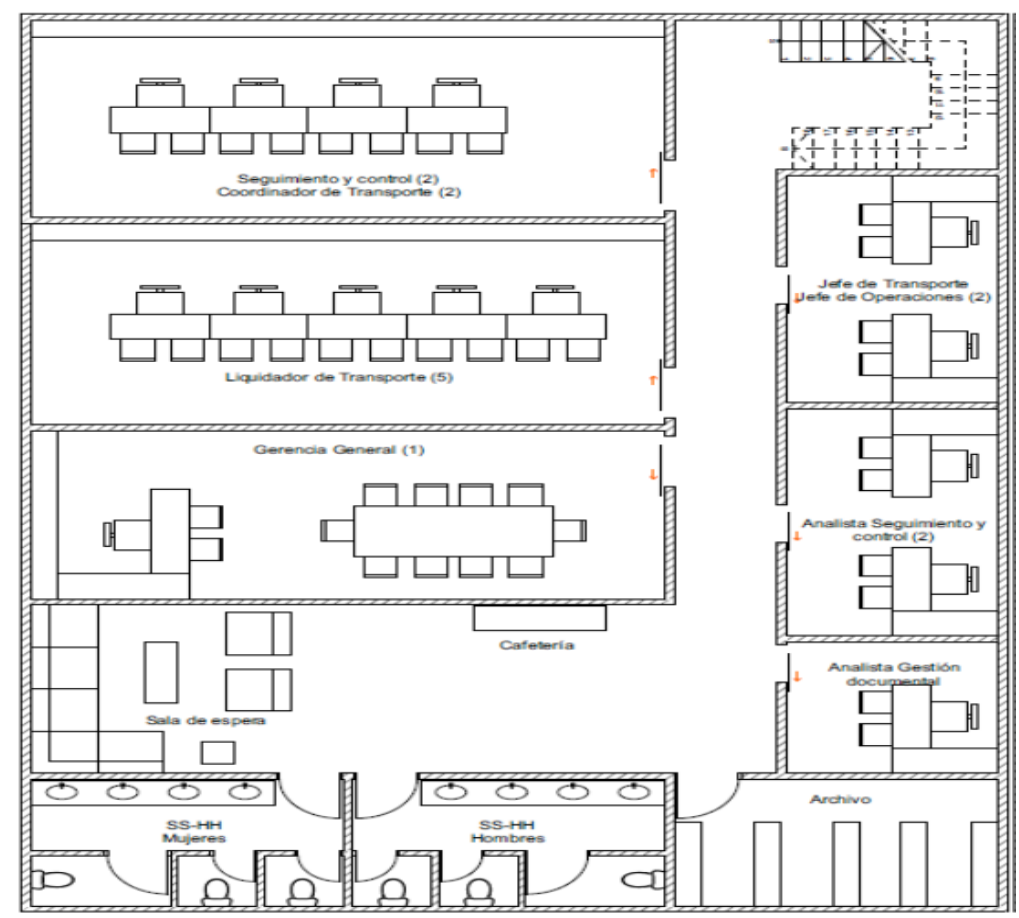

Figura 5. División espacial para la empresa Transnexos

Fuente: Empresa Transnexos, 2019. 


\section{Gestión por Procesos}

Para lograr la mejora en la productividad mencionada anteriormente, se plantea la gestión por procesos que comprenden el desarrollo de manera ordenada y controlada de las actividades, para ello se elaboraron los siguientes flujogramas:

\section{- Flujograma de Asignación de Vehículos}

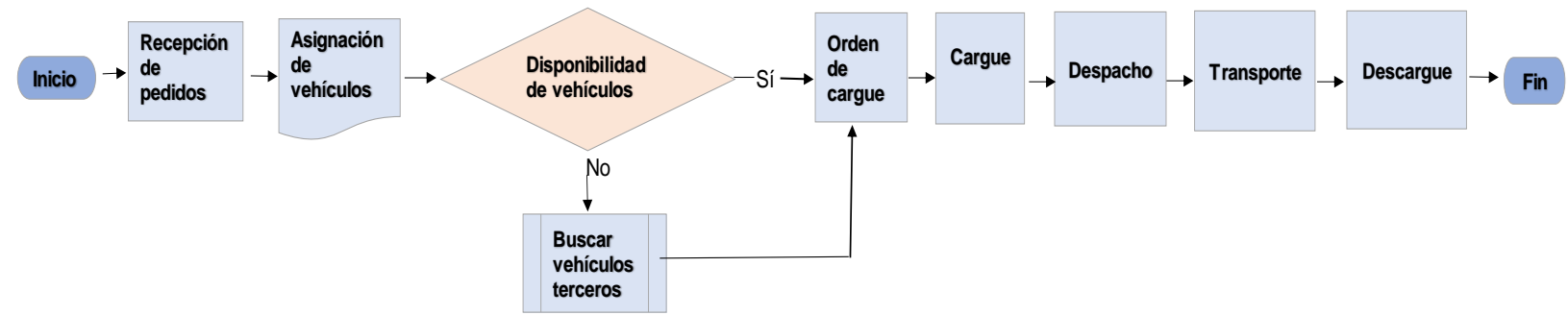

Figura 6. Flujograma de Asignación de Vehículos

Fuente: Empresa Transnexos, 2019.

\section{- $\quad$ Flujograma de Seguimiento y Control}

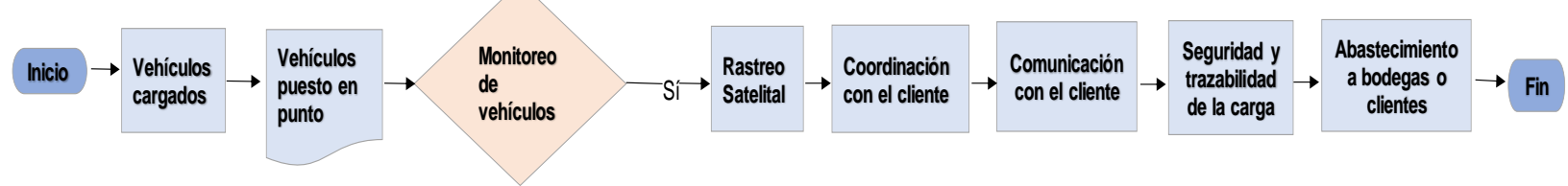

Figura 7. Flujograma de Seguimiento y Control

Fuente: Empresa Transnexos, 2019.

\section{- $\quad$ Flujograma de Liquidación de Transporte}

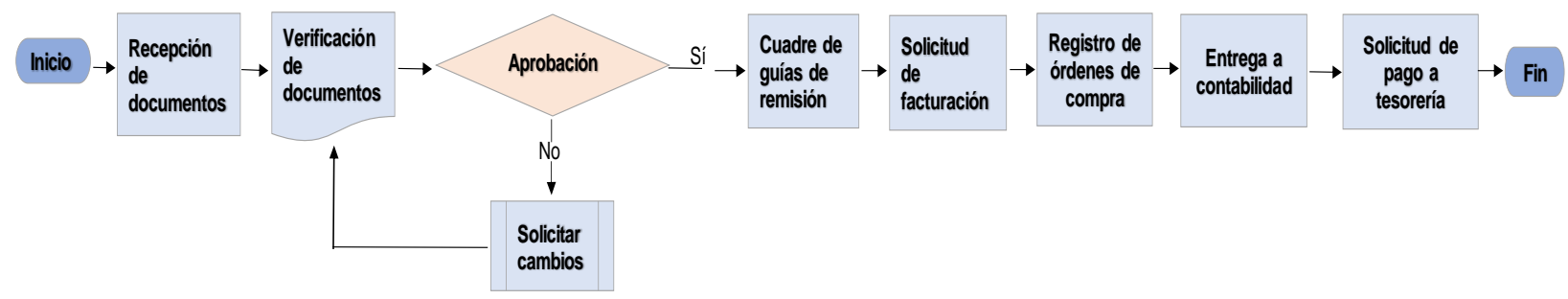

Figura 8. Flujograma de Liquidación de Transporte

Fuente: Empresa Transnexos, 2019. 


\section{- $\quad$ Flujograma de Gestión Documental}

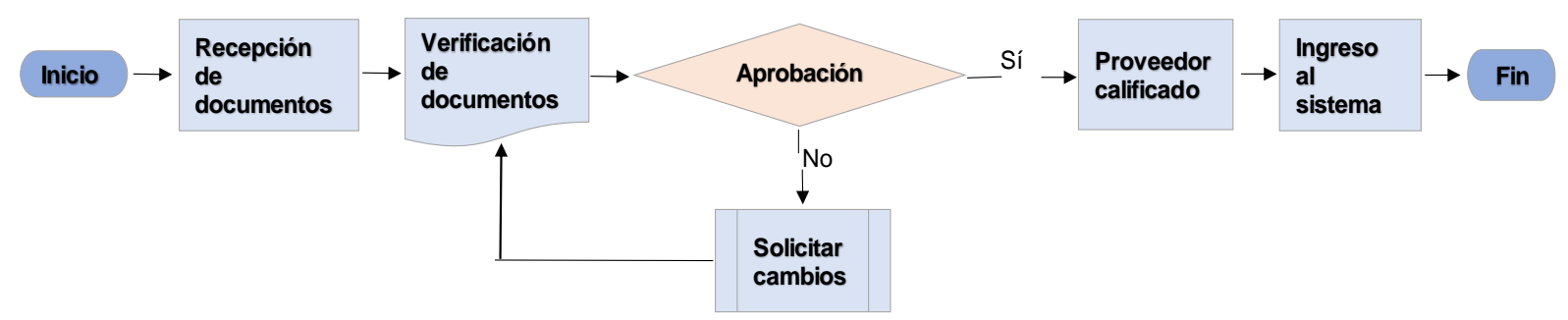

Figura 9. Flujograma de Gestión Documental

Fuente: Empresa Transnexos, 2019.

\section{Capacidad Instalada}

Para obtener la correcta gestión por procesos se requiere de los siguientes recursos:

\section{- Personal}

\section{Tabla 16}

Personal para atender a Clientes Internos

\begin{tabular}{lllr} 
N $^{\circ}$ Cargo & Cantidad & Cargo & Sueldo \\
\hline 1 & 4 & Liquidador de Transporte & 36,667 \\
2 & 3 & Analista de Seguimiento & 33,295 \\
3 & 14 & Chofer de Tráiler & 148,629 \\
4 & 4 & Chofer de Volquete & 40,015 \\
5 & 3 & Coordinador de Transporte & 27,707 \\
6 & 1 & Gerente General & 6,500 \\
7 & 1 & Jefe de Operaciones & 9,287 \\
8 & 1 & Jefe de Transporte & 17,744 \\
9 & 1 & Paramédico & 12,872 \\
10 & 1 & Presidente & 6,500 \\
& 33 & Total & $\mathbf{3 3 9 , 2 1 6}$ \\
\hline
\end{tabular}

Fuente: Empresa Transnexos, 2019. 


\section{Tabla 17}

Personal para atender a Clientes Externos

\begin{tabular}{lllr}
$\mathbf{N}^{\circ}$ Cargo & Cantidad & Cargo & \multicolumn{1}{c}{ Sueldo } \\
\hline 1 & 1 & Liquidador de Transporte & 9,167 \\
2 & 1 & Analista de Seguimiento & 11,098 \\
3 & 10 & Chofer de Tráiler & 106,164 \\
4 & 1 & Coordinador de Transporte & 9,236 \\
& $\mathbf{1 3}$ & Total & $\mathbf{1 3 5 , 6 6 5}$ \\
\hline
\end{tabular}

Fuente: Empresa Transnexos, 2019.

\section{- Activos Fijos}

\section{Tabla 18}

Detalle para cubrir vehículos para cubrir rutas de los Clientes Internos

\begin{tabular}{lrrr} 
Descripción & Cantidad & Valor en libros \\
\hline Tráiler Freightliner & 7 & \multicolumn{2}{c}{ (269,128 } \\
Cabezal-T Mercedez Benz & 2 & & \\
& & 292,653 & 80,172 \\
Volqueta Internacional & 3 & 27,382 \\
Camión Hino & 1 & 1,059 \\
Tráiler Mack & 2 & 441 \\
Tráiler Internacional & 1 & 69 \\
Tráiler Ford & 1 & \\
Subtotal & $\mathbf{1 7}$ & $\mathbf{7 7 0 , 9 0 4}$ \\
& & &
\end{tabular}

Fuente: Empresa Transnexos, 2019.

\section{Tabla 19}

Detalle para cubrir vehículos para cubrir rutas de los Clientes Externos

\begin{tabular}{clccc}
$\begin{array}{l}\mathbf{N}^{\circ} \\
\text { vehículos }\end{array}$ & Tipo de vehículo & $\begin{array}{c}\text { Capacidad } \\
\text { (ton) por } \\
\text { vehículo }\end{array}$ & $\begin{array}{l}\text { Valor } \\
\text { unitario }\end{array}$ & $\begin{array}{l}\text { Valor } \\
\text { Total }\end{array}$ \\
\hline 10 & $\begin{array}{l}\text { Tráiler } \\
\text { Freightliner }\end{array}$ & 30 & 134,000 & $1,273,000$ \\
\hline
\end{tabular}

Fuente: Empresa Transnexos, 2019. 


\section{Tabla 20}

Detalle equipo de computación

Fuente: Empresa Transnexos, 2019.

\begin{tabular}{lr} 
Descripción & \multicolumn{1}{c}{ Total } \\
\hline Alquiler computadoras & 3,433 \\
Servicios de mantenimiento & 1,705 \\
Licencias & 3,914 \\
Subtotal & $\mathbf{9 , 0 5 2}$ \\
\hline
\end{tabular}

\section{Estrategias de Marketing}

\section{Estrategia de precio}

Los precios con lo que trabaja Transnexos están regulados al precio de mercado, apegados con la estructura de costos operativos, de acuerdo con la ruta asignada.

\section{Estrategia de publicidad}

Dado que la empresa Transnexos no tiene publicidad, se planteó como estrategia de marketing a desarrollar el posicionamiento en medios digitales por lo que se ha considerado la posibilidad de crear la página web en donde se pueda indicar los servicios y beneficios que ofrece la empresa, entrega de afiches a los clientes que visiten los locales comerciales del Grupo Industrial Graiman, y una campaña publicitaria en redes sociales (Facebook, Linkedln).

\section{Presupuesto de Marketing}

\section{Tabla 21}

Presupuesto de marketing para la empresa Transnexos

\begin{tabular}{|c|c|c|c|c|}
\hline Estrategia & Descripción & $\begin{array}{l}\text { Gasto } \\
\text { por mes }\end{array}$ & $\begin{array}{l}\mathrm{N}^{\circ} \text { de } \\
\text { meses }\end{array}$ & $\begin{array}{l}\text { Gasto } \\
\text { anual }\end{array}$ \\
\hline \multirow{3}{*}{$\begin{array}{lr}\text { Posicionamiento de } \\
\text { la empresa } \\
\text { Transnexos en }\end{array}$} & \multicolumn{2}{|l|}{ Hosting y dominio web } & 12 & 100 \\
\hline & \multicolumn{2}{|l|}{ Diseño y programación web } & 12 & 1,000 \\
\hline & $\begin{array}{l}\text { Campaña publicitaria en medios digitales } \\
\text { (Facebook, Linkedln) }\end{array}$ & 500 & 6 & 3,000 \\
\hline \multirow{3}{*}{ medios digitales } & $\begin{array}{l}\text { Contrato de soporte y mantenimiento de la } \\
\text { página web }\end{array}$ & 200 & 6 & 1,200 \\
\hline & Honorarios diseñador web & 600 & 6 & 3,600 \\
\hline & Elaboración de 2.000 afiches & 600 & 2 & 1,200 \\
\hline TOTAL & & 1,900 & & 10,100 \\
\hline
\end{tabular}

Fuente: Empresa Transnexos, 2019. 


\section{Estrategias de Inversión}

\section{Inversión}

Para estimar el número de vehículos que la empresa Transnexos necesita para expandir su negocio y cubrir los envíos de los clientes externos, se consideró de acuerdo con: el número de viajes a realizar al mes para cada destino y el número de envíos al mes, sabiendo que cada vehículo tiene como capacidad total 30 toneladas de carga y la capacidad enviada será de 15 toneladas, obteniendo como resultado que se necesita 10 vehículos.

Los vehículos que la empresa Transnexos tiene en la actualidad son 17, los mismos cubren las rutas en total de su capacidad para los clientes internos por lo que se tiene la necesidad de invertir en 10 vehículos para cubrir las rutas de los clientes externos.

\section{Tabla 22}

Detalle de vehículos a requerir para expansión del negocio Transnexos

\begin{tabular}{rlrrr}
$\begin{array}{l}\mathbf{N}^{\circ} \\
\text { vehículos }\end{array}$ & Tipo de vehículo & $\begin{array}{l}\text { Capacidad (ton) } \\
\text { por vehículo }\end{array}$ & $\begin{array}{l}\text { Valor } \\
\text { unitario }\end{array}$ & $\begin{array}{l}\text { Valor } \\
\text { Total }\end{array}$ \\
\hline 10 & $\begin{array}{l}\text { Tráiler } \\
\text { Freightliner }\end{array}$ & 30 & 134,000 & $1,273,000$ \\
& & & \\
\hline
\end{tabular}

Fuente: Empresa Transnexos, 2019.

\section{Financiamiento}

El financiamiento será mediante un préstamo solicitado en el Banco del Pacífico en el que la empresa Transnexos se encuentra calificada, la tasa anual será $8.95 \%$ con un plazo de 10 años. 


\section{Tabla 23}

Plan de financiamiento para la empresa Transnexos

Fuente: Empresa Transnexos, 2019.

\begin{tabular}{ll} 
Tasa Anual & $8.25 \%$ \\
\hline $\mathrm{N}^{\circ}$ de pagos & 10 \\
Valor deuda & $\$ 1,273,000$ \\
Cuota mensual & $\$ 15,614$ \\
\hline
\end{tabular}

En la tabla 22 se muestra las cuotas a pagar durante cada año, junto con el desglose de interés y capital.

\section{Tabla 24}

Tabla de amortización de la deuda para la empresa Transnexos

\begin{tabular}{|c|c|c|c|}
\hline \multirow[b]{2}{*}{ Año } & \multirow[t]{2}{*}{ Cuota } & \multicolumn{2}{|c|}{ Amortizaciones } \\
\hline & & Interés & Capital \\
\hline 1 & $\$ 187,364$ & $\$ 101,836$ & $\$ 85,528$ \\
\hline 2 & $\$ 187,364$ & $\$ 94,507$ & $\$ 92,857$ \\
\hline 3 & $\$ 187,364$ & $\$ 86,550$ & $\$ 100,814$ \\
\hline 4 & $\$ 187,364$ & $\$ 77,911$ & $\$ 109,453$ \\
\hline 5 & $\$ 187,364$ & $\$ 68,532$ & $\$ 118,832$ \\
\hline 6 & $\$ 187,364$ & $\$ 58,349$ & $\$ 129,015$ \\
\hline 7 & $\$ 187,364$ & $\$ 47,294$ & $\$ 140,071$ \\
\hline 8 & $\$ 187,364$ & $\$ 35,291$ & $\$ 152,073$ \\
\hline 9 & $\$ 187,364$ & $\$ 22,259$ & $\$ 165,105$ \\
\hline 10 & $\$ 187,364$ & $\$ 8,111$ & $\$ 179,253$ \\
\hline Total & $\$ 1,873,642$ & $\$ 600,642$ & $\$ 1,273,000$ \\
\hline
\end{tabular}

Fuente: Empresa Transnexos, 2019.

\section{CONCLUSIONES}

Se concluye que existe la factibilidad de incorporar una línea de ingresos que brinde el servicio de transporte a los clientes externos, con el objetivo de incrementar la rentabilidad de la empresa Transnexos. El estudio financiero desglosa costos operativos para cada línea de ingresos (clientes internos en la actualidad y clientes externos), con los que se determinaron el costo de venta.

Para la estimación del ingreso de los clientes externos se determinó a través del estudio de mercado realizado, el mismo ayudo a evaluar el número de viajes al mes y el lugar de 
destino a donde se requiere enviar el material, con lo que ayudo a estimar las rutas necesarias. Se evaluó el requerimiento del número de vehículos con la capacidad necesaria para cubrir las rutas de los clientes externos, de manera de que se pueda valorar la inversión.

Con el desarrollo del plan de acción y los resultados obtenidos en el cálculo del VAN positivo de 26.114 dólares y una TIR de 9.07\% siendo mayor a la TMAR requerida, se considera el proyecto viable generando utilidades positivas y cumpliendo el objetivo planteado.

\section{REFERENCIAS CONSULTADAS}

1. Blanco Bello, V., Machado Castillo, J., \& Tornes Olivera, N. (2019). Evaluación de tres momentos de riego en el cultivo de la sábila en el Municipio Colina, Falcón. Venezuela. Revista Arbitrada Interdisciplinaria Koinonía, 4(7), 280-292. doi:http://dx.doi.org/10.35381/r.k.v4i7.205

2. Castelán Valdivia, A., \& Oros Méndez, L. A. (01 de Enero de 2011). Importancia de un Plan de Negocios. Contribuciones a la Economía. Obtenido de Contribuciones a la Económia: http://www.eumed.net/ce/2011b/

3. CFN, C. F. (2017). Transporte de carga por carretera. Cuenca: Sugerencia de análisis e información.

4. Faga, H., \& Ramos, M. (2006). Cómo conocer y manejar sus costos para tomar decisiones rentables. Buenos Aires: Granica S.A.

5. GAD, G. M. (2015). Plan de movilidad y espacios públicos. Cuenca: GAD Municipal Cuenca.

6. Goercke Villarreal, J. R., Erazo Álvarez, J. C., Narváez Zurita, C. I., \& Quevedo Vázquez, J. O. (2019). Plan de negocio, proyecto constructora BellaTerra en la ciudad de Cuenca, Ecuador. Visionario Digital, 185.

7. Herbas, J. (2019). Métodos de Localización para un Proyecto. Obtenido de Academia.edu:

https://www.academia.edu/5288401/METODOS_DE_LOCALIZACION_PARA_U

N_PROYECTO_M\%C3\%89TODO_CUALITATIVO_POR_PUNTOS 
8. Hernández Sampieri, R., \& Fernández Collado, C. B. (2014). Metodologia de la Investigación. México: MCGRAW-HILL.

9. INEC. (2019). Resultados Indice de precios al consumidor. Cuenca: INEC.

10. INFOCIF, R. (23 de Junio de 2015). Qué es y cómo se elabora un plan de expansión. Obtenido de Qué es y cómo se elabora un plan de expansión: https://noticias.infocif.es/noticia/que-es-y-como-se-elabora-un-plan-de-expansion

11. Maqueda Lafuente, J. (2010). Marketing, innovación y nuevos negocios. España: ESIC editorial.

12. Montero Tapia, I. F., Erazo Álvarez, J. C., Narváez Zurita, C. I., \& Ormaza Andrade, J. E. (2019). Desarrollo organizacional como estrategia de modernización de la calidad del servicio de alimentos y bebidas. Visionario Digital, 111.

13. Ochoa, C. (29 de mayo de 2015). Muestreo no probabilistico: muestreo por conveniencia. Obtenido de Muestreo no probabilistico: muestreo por conveniencia: https://www.netquest.com/blog/es/blog/es/muestreo-por-conveniencia

14. Puente Riofrío, M. I., \& Carrasco Salazar, V. A. (2017). Plan de negocios una guía empresarial para pequeños negocios. Revista Observatorio de la Economía Latinoamericana, 2.

15. Truex, L. (s.f.). Como crear un plan de negocios de expansión. Obtenido de Como crear un plan de negocios de expansión: https://pyme.lavoztx.com/cmo-crear-unplan-de-negocios-de-expansin-4252.html

16. Trust, B. (2009). Técnicas para la Optimización de Rutas de Transporte y Distribución . Brain Trust Consulting services, 4.

17. Viniegra Rocío, S. (2007). Entendiendo el Plan de Negocios. España: Lulu.com.

18. Weinberger Villarán, K. (2009). Plan de Negocios Herramienta para evaluar la viabilidad de un negocio. Perú: Nathan Associates Inc, 2009.

\section{REFERENCES CONSULTED}

1. Blanco Bello, V., Machado Castillo, J., \& Tornes Olivera, N. (2019). Evaluation of three irrigation moments in the cultivation of aloe in the Municipality of Colina, Falcón. Venezuela. Interdisciplinary Arbitrated Review Koinonía, 4 (7), 280-292. doi: http: //dx.doi.org/10.35381/r.k.v4i7.205 
2. Castelán Valdivia, A., \& Oros Méndez, L. A. (January 1, 2011). Importance of a Business Plan. Contributions to the Economy. Obtained from Contributions to the Economy: http://www.eumed.net/ce/2011b/

3. CFN, C. F. (2017). Freight transport by road. Cuenca: Analysis and information suggestion.

4. Faga, H., \& Ramos, M. (2006). How to know and manage your costs to make profitable decisions. Buenos Aires: Granica S.A.

5. GAD, G. M. (2015). Mobility plan and public spaces. Cuenca: GAD Municipal Cuenca.

6. Goercke Villarreal, J. R., Erazo Álvarez, J. C., Narváez Zurita, C. I., \& Quevedo Vázquez, J. O. (2019). Business plan, BellaTerra construction project in the city of Cuenca, Ecuador. Digital Visionary, 185.

7. Herbas, J. (2019). Location Methods for a Project. Obtained from Academia.edu: https://www.academia.edu/5288401/METODOS DE LOCALIZACION PARA U N PROYECTO M\%C3\%89TODO CUALITATIVO POR PUNTOS

8. Hernández Sampieri, R., \& Fernández Collado, C. B. (2014). Investigation methodology. Mexico: MCGRAW-HILL.

9. INEC. (2019). Results Consumer price index. Basin: INEC.

10. INFOCIF, R. (June 23, 2015). What it is and how an expansion plan is elaborated. Obtained from What is and how an expansion plan is elaborated: https://noticias.infocif.es/noticia/que-es-y-como-se-elabora-un-plan-de-expansion

11. Maqueda Lafuente, J. (2010). Marketing, innovation and new business. Spain: ESIC editorial.

12. Montero Tapia, I. F., Erazo Álvarez, J. C., Narváez Zurita, C. I., \& Ormaza Andrade, J. E. (2019). Organizational development as a strategy to modernize the quality of the food and beverage service. Digital Visionary, 111.

13. Ochoa, C. (May 29, 2015). Non-probabilistic sampling: convenience sampling. Obtained from non-probabilistic sampling: convenience sampling: https://www.netquest.com/blog/es/blog/es/muestreo-por-conveniencia

14. Puente Riofrío, M. I., \& Carrasco Salazar, V. A. (2017). Business plan a business guide for small businesses. Latin American Economy Observatory Magazine, 2. 
15. Truex, L. (s.f.). How to create an expansion business plan. Obtained from How to create an expansion business plan: https://pyme.lavoztx.com/cmo-crear-un-plande-negocios-de-expansin-4252.html

16. Trust, B. (2009). Techniques for the Optimization of Transportation and Distribution Routes. Brain Trust Consulting services, 4.

17. Viniegra Rocío, S. (2007). Understanding the Business Plan. Spain: Lulu.com.

18. Weinberger Villarán, K. (2009). Business Plan Tool to evaluate the viability of a business. Peru: Nathan Associates Inc, 2009. 